\title{
Você acaba se tornando você mesmo? O personagem David Foster Wallace
}

\author{
Marcos Namba Beccari ${ }^{1}$
}

\begin{abstract}
Resumo: Este artigo propõe uma reflexão sobre o mito literário atrelado ao nome David Foster Wallace após o suicídio do autor. Tal reflexão elege como alvo a versão retratada em $O$ fim da turnê (James Ponsoldt, 2015), filme repu diado por familiares e colegas próximos de Wallace. De início, justifico a esco lha de encarar DFW como personagem. Na sequência, discuto sobre a noção chave da dissimulação em DFW, que elucida o dilema entre quem ele dizia ser e o possível personagem de si mesmo. Por fim, reconstruo a querela em torno do filme ora elencado e defendo a dissimulação wallaceana enquanto potência fabuladora que enaltece a ambiguidade.
\end{abstract}

Palavras-chave: David Foster Wallace; dissimulação; personagem de si.

\section{Introdução}

Ninguém entende ós motivos de um suicida. Ninguém. A única pessoa talvez capaz de entendê los é morta pelo ato. (GALINDO, 2014, s. p.)

Este ensaio não trata de suicídio, enquanto ato intencional de pôr fim à própria vida, e sim do mito literá rio que o nome David Foster Walla ce representa após o suicídio do au tor. A tal advertência devo acres centar outra: falar sobre Wallace, "um autor universalmente reco nhecido por ter sido expressamente obcecado com a mediação em todas as suas formas paradoxais" (CO HEN; KONSTANTINOU, 2012, p. xi) ${ }^{2}$, implica assumir a impostura de que seu nome será uma vez mais distorcido, duplicado, enviesado, tornado enfim personagem. Mas reitero o primeiro ponto: não resta aqui o menor interesse sobre o que levou, Wallace, o indivíduo, a ter se enforcado há dez anos. Proponho apenas uma reflexão sobre o perso nagem DFW após o suicídio de Wallace ${ }^{3}$.

Mais precisamente, parte $\sim$ se da seguinte analogia: se é verdade, como Caetano Galindo afirma na citação inicial, que ninguém pode entender os motivos de um(a) sui cida, talvez seja igualmente inapro priado explicar o que leva, necessa riamente, um(a) escritor(a) a escre ver. E isso é válido mesmo quando quem explica é o(a) próprio(a) es critor(a), posto que em todo caso se abre, ao estilo de. Wallace, um ciclo tautológico interminável: por que escrever sobre "por que escrever"? E explicar a si mesmo(a) não impli caria criar (mais) um personagem de si?
${ }^{1}$ Professor Adjunto na UFPR. Doutor em Educação pela USP. Contato: conta to@marcosbeccari. com.

${ }^{2}$ Esta e as demais citações em língua estrangeira foram por mim traduzi das.

${ }^{3}$ Neste artigo, a sigla DFW refere $\sim$ se ao personagem, ao passo que "Walla ce" se refere ao autor. 
Alguém poderia, ainda, escrever sem ter motivo algum, de modo que qualquer justificativa não the impe diria de continuar a fazê $l o$. Fato é que a escrita se põe em ato sem ga rantias e quase que de maneira in justificável. Digo "quase" porque justificativas não faltam, ao mesmo tempo em que estas dependem elas próprias da escrita. A escrita tende a incorporar, nesse sentido, a tenta tiva paradoxal de expressar a pró pria possibilidade da escrita. Inspi ro me aqui na asserção de Derrida (1971, p. 24) segundo a qual as palavras sempre mostram algo ain da não pensado a quem as escreve, elas "ensinam o seu pensamento". Talvez seja por isso que a escritora Marguerite Duras (1994, p. 22) tenha afirmado que "a escrita é o desconhecido", posto que, "antes de escrever, nada se sabe do que se vai escrever" (DURAS, 1994, p. 47).

A obra de Wallace é claramente obcecada por essa lógica paradoxal da escrita, como um gesto perfeita mente absurdo e indefensável: es crever em pleno conhecimento de causa, entre a lucidez e a contradi ção permanente. Em uma palavra, escrever para poder escrever. Não será, contudo, diretamente a obra wallaceana o alvo a sér aqui explo rado, mas uma versão polêmica do personagem DFW: aquela retratada no filme $O$ fim da turnê (The End of the Tour, James Ponsoldt, 2015), baseado no best-seller de David Lipsky (2010), Although of course you end up becoming yourself ("Mas é claro que você acaba se tornando você mesmo"). Mais complicado ainda: o aspecto polê mico não reside no filme ou no li vro de Lipsky, mas no fato de que os familiares e colegas próximos de Wallace manifestaram repúdio con tra o filme/livro.

Com efeito, o personagem (do la tim persona, literalmente "pelo som", mas também máscara de ator, personagem teatral) DFW será aqui reconstruído a partir de algumas de suas versões póstumas em contra posição com a querela em torno do filme de Ponsoldt. Não é o caso, ob viamente, de decidir sobre qual é a versão verídica ou a mais interes sante. $\mathrm{O}$ que se coloca em questão são as possibilidades teóricas que se abrem a partir da relação dissimu lada entre quem DFW dizia ser e o possível personagem de si mesmo questão que, uma vez transposta ao cinema, passa a ser indiretamente associada ao suicídio de um perso nagem, e nãó mais ao de um indiví duo vagamente designado como autor.

\section{DFW após o suicídio de Wallace}

David Foster Wallace nasceu em Ithaca, cidade do estado de Nova Iorque e homônima à ilha natal do 'protagonista da Odisseia. Esse deta the trivial serve nos apenas para indicar que, assim como geralmente nos referimos a Homero, o mito DFW interessa nos mais que o au tor, a pessoa, o suicida. Tal perso nagem não aparece diretamente na obra de Wallace, embora esteja ine vitavelmente atrelado a ela, e sim no modo como seu nome é enunci ado, suscitado, aludido ou vincula - 
do a narrativas diversas.

A este respeito, cumpre mencio nar que foram publicados até o momento dezessete livros sobre DFW; o website The Howling Fan tods reúne pesquisas sobre DFW desde 1997; o arquivo completo de DFW é mantido deśde 2010 na Universidade do Texas ${ }^{4}$. A primeira biografia de DFW foi publicada em 2012, por D. T. Max, com o título Every love story is a ghost story: a life of David Foster Wallace, des pontando entre os livros mais ven didos dos EUA naquele ano. Tam bém em 2012 foi publicada The Legacy of $D F W$, uma seleção "defi nitiva" de artigos acadêmicos orga nizada por Samuel Cohen e Lee Konstantinou. Em 2014, a editora Bloomsbury, depois de já ter publi cado seis antologias de estudos crí ticos sobre o trabalho de DFW, pu blicou simultaneamente mais duas: Gesturing Toward Reality: David Foster Wallace and Philosophy, or ganizada por Robert K. Bolger e Scott Korb, e David Foster Wallace and "The Long Thing": New Essays on the Novels, organizada por Marshall Boswell. Em 2017 foram inaugurados, por fim, o Journal of DFW Studies e a International DFW. Society, onde convergem cursos, conferências, dossiês etc. que são regularmente dedicados a DFW.

Ou seja, em menos de dez anos após o suicídio de Wallace, em 2008, a quantidade de publicações sobre o autor ultrapassou expressi vamente o número de livros que ele publicou em vida 5 . DFW tornou - se rapidamente um novo cânone da literatura norte americana, cujos rótulos póstumos se destacam: "pós humanismo sentimental", "nova sinceridade" e "crença pós irônica" em resposta a uma herme nêutica da suspeita ${ }^{6}$.

De um lado, a reputação acadê mica da obra wallaceana tem se servido de um revestimento de or todoxia que tende a relativizar, ou mesmo a inverter, a mera sensibili dade romântica amiúde associada a DFW. De outro, a repercussão do suicídio de Walláce reforçou a ideia de que sua escrita era uma luta permanente contra a solidão e os efeitos incapacitantes da depressão, o que faz prevalecer o hábito de interpretar sua obra como sintoma ou sublimação de suas experiências psíquicas.

Nesse sentido, de acordo com Ana Cecília Carvalho (2010, p. 520), a escrita de DFW é "marcada por uma tensão potencialmente destrutiva que, no seu caso, era alimentada por dois horrores: o horror de nada dizer e o de tudo dizer". Por sua vez, Lee Konstanti nou (2012, p. 105) considera que "seu suicídio pode ser descrito co mo uma falha da literatura em al cançar sua promessa, sua incapaci dade de resolver problemas". Para Mary K. Holland (2013, p. 77), en tretanto, o/projeto de DFW (ficção e não ficção) deve ser dissociado do autor depressivo, pois sua maior contribuição teria sido uma "rever são do pós estruturalismo de dentro do próprio pós estruturalismo": em vez de recorrer às frágmentações textuais, formais e psíquicas que Holland associa à tendência anti humanista do pós estruturalismo,
${ }^{4}$ Cf.: <https:// davidfosterwal laceresearch. wordpress.com/>, $<$ http://thehowli ngfantods.com/ $\mathrm{dfw} />$

$<$ http://www.hrc. utexas.edu/press $/$ releases $/ 2010 / d$ $\mathrm{fw} />$. Acesso em: 04 set. 2018.

${ }^{5}$ Em vida, Wallace publicou apenas nove livros: dois romances, três coleções de contos, duas coletâneas de ensaios (não ficção) e dois livros teóricos (um sobre a história do conceito matemá tico de "infinito", e o outro, em coautoria com Mark Costello, sobre a cultura hip hop norte americana).

${ }^{6} \mathrm{Cf}$. respectiva mente: GILES, 2007; KELLY, 2010; KONSTAN TINOU, 2012. 
DFW teria inaugurado um momen to de "empatia direta" entre o leitor e "o autor ressuscitado" (HOL LAND, 2013, p. 78).

Embora esse debate se estenda para além do recorte aqui delinea do, serve nos para enquadrar uma incompreensão que ainda paira em torno do nome DFW: quem era ele, afinal? Um romântico obcecado pe la sinceridade autoral, tanto quanto pela revisão e notas de rodapé que preenchem seus textos? E/ou um dos grandes autores da literatura pós moderna? Nesse caso, de qual literatura pós moderna? Aquela de uma metaficção (ou ficção autobio gráfica), tendência que já parecia fatigada em meados dos anos 1990 e que, a partir de então, DFW pre feria não assumir? Ou aquela que reinveste na crença romântica da autenticidade individual, a despeito do sofisticado cinismo wallaceano e sua permanente suspeita "de que poderíamos ser nada mais do que discursos ou pretensões ou ironias" (COHEN; KONSTANTINOU, 2012, p. xvii)?

Mantém -se em aberto, com efei to, a profunda ambivalência (ou desconfiança) de DFW não apenas em relação ao legado pós moderno, mas também para consigo mesmo, como explano adiante. E apesar de haver, por um lado, inúmeros depoimentos em que Wallace nos conta sobre sua própria escrita, por outro, "tanto as escolas quanto as disposições intelectuais concorda ram que o autor não tem nada a nos dizer sobre o que seus textos signi ficam" (COHEN; KONSTANTINOU, 2012, p. xii xiii). Nos termos de
Paul Ricoeur (2011, p. 29), "o fato de ser escrito faz do discurso o por tador de uma história que já não é a de seu autor". Então qual o interes se em deter se sobre alguém que não tem nenhuma importância? Por que julgar o autor sobre aquilo que em larga medida ele mesmo já ex plicou?

Eis a questão do personagem: não se trata de assimilá lo como uma identidade unificada, mas de pensar como ele pode ser reinterpretado, retratado, reconstruído a partir de fragmentos dispersos. Alguns o fa zem direcionando se à biografia do autor, enquanto outros debruçam se sobre sua obra. Outros, ainda, reconstroem DFW a partir dos ra biscos que ele deixava nas margens de cada página que passava por su as mãos, anotações infindáveis que "parecem colocar o autor 'sempre do 'nosso 'óuvido' enquanto ele transmite suas notas de pensamen to" (ROACHE, 2015, p. 26). Seja como for, toda reconstrução é cir cunstancial, pois depende de uma configuração pontual no interior de uma determinada situação interpre tativa. No caso do foco aqui traça do, importa me enquadrar DFW a partir do recurso da dissimulação, que elucida o dilema entre quem ele dizia ser e o possível personagem de si mesmo.

\section{A dissimulação de DFW: autor ou personagem de si mesmo}

Parece que a grande distinção entre a boa arte e a arte ruim reside no desejo que o escritor tem de morrer 
para emocionar o leitor. Toda a atenção, dedicação e trabalho que precisa obter do leitor não pode ser para benefício próprio; tem de ser em benefício do leitor (WALLACE apud MAX, 2009, s. p.).

Para evitar a intentional fallacy ${ }^{7}$ da questão sobre quem DFW de fato acreditava ser, permito me inferir sobre como ele encarava a noção de autoria. DFW demonstrou conhe cimento e interesse nas teorias aca dêmicas sobre a autoria literária, conforme John Roache (2015) des taca em sua pesquisa das anotações marginais wallaceanas, e conforme o próprio Wallace $(1997$, p. 138 145) sinaliza em Greatly Exaggera ted, sua resenha de Morte d'Author: An Autopsy de H. L. Hix. Em síntese, "A noção teórica da morte do autor é uma ideia bastante interessante, Wallace parece dizer, mas não é algo que devamos levar a sério" (ROACHE, 2015, p. 87). Isso por que DFW destacava com frequência a dimensão comunicacional da es crita, encarando a como a arte de se comunicar com leitores. Sob esse viés, a ênfase não recai no insondá vel processo de criação da obra, mas nas técnicas mediante as quais uma obra se torna comunicável.

Tal abordagem aproxima se par cialmente da proposta de Wayne Booth (1983), cujo conceito de "au' tor implícito" ou "autor implicado" (implied author) distingue se tanto do autor real quanto do narrador, emergindo somente pela leitura, portanto com base na forma como o texto é estruturado. Disso resulta que o apagamento do autor pode ser encarado como uma técnica re tórica entre outras: "Embora o au tor possa em certa medida escolher seus disfarces, nunca pode escolher desaparecer de todo" (BOOTH, 1983, p. 20). Para Paul Ricoeur (2010, p. 285), entretanto, "Numa perspectiva puramente retórica, o leitor é, no limite, simultaneamente presa e vítima da estratégia fomen tada pelo autor implicado, e isso tanto mais quanto mais dissimulada for essa estratégia".

DFW parecia' ter 'consciência, nesse sentido, de que o trabalho de leitura é não apenas indeterminá vel, mas igualmente dissimulável, podendo escapar em larga medida da retórica que lhe torna passivo. Ou seja, apesar de toda leitura pres supor uma busca de coerência, tal coerência não subsiste por trás do texto, à espera de ser decifrada, mas emerge no confronto com as pretensões e retenções de cada leitura. Nesse jogo, os sinais dispersos do autor podem ter sido dissimulados na mesma medida em que os leito res "querem fingir que acreditam", conforme DFW (2005, p. 170 171, destaques meus) enuncia em uma das Breves entrevistas com homens hediondos.

"Você é, infelizmente, um escritor de ficção. Está tentando um ciclo de peças beletristas muito curtas... Di fícil descrever como as peças curtas do ciclo devem funcionar... Você tem certeza, porém, de que as peças narrativas são realmente apenas "peças" e nada mais, i. 'e., que a maneira como elas se encaixam no ciclo maior que as compreende é que é crucial para a "alguma coisa" que você quer "questionar" numa sensação humana e assim por dian
7 "Falácia intenci onal", de acordo com The Concise Oxford Compani on to English Literature, é um termo cunhado em 1946 pelos críti cos norteamericanos W. K. Wimsatt Jr. e Monroe C. Beards ley, ao postularem que qualquer suposição sobre a intenção do autor deve ser testada contra a evidência do texto. Disponí vel em:

$<$ http://www.oxf ordreferen -

ce.com/view/10.1 093/oi/authority. 20110803100006 219>. Acesso em: 04 set. 2018. 
te. Então você faz um ciclo de oito partes dessas pequenas" peças de porca e parafuso. E resulta num fi asco total... Mesmo com a mais ca ridosa interpretação, isso vai pare cer desesperado. Possivelmente pa tético. De qualquer forma, não vai fazer você parecer sábio, nem segu ro, nem dotado, nem qualquer das coisas que os leitores geralmente querem fingir que acreditam que o artista literário que escreveu o que estão lendo é, quando sentam para tentar escapar do insolúvel fluxo de si mesmos e entrar em um mundo de significado preestabelecido.

À primeira vista, DFW parece es tabelecer certa simetria entre um autor implicado e um leitor impli cado, ambos tidos como construções fictícias. Esse modelo, no entanto, não deixa de atuar também como explicação fictícia de como o texto de ficção adquire sentido. Donde é possível presumir que a dimensão comunicacional da escrita é, para DFW, uma luta não necessariamen te simétrica entre duas orientações divergentes: de um lado, a ficção evoca a si mesma conforme a ênfase recaia nos personagens, na intriga, na voz narrativa e finalmente nas sucessivas posições atribuídas ao leitor; de outro, contrariando essa tendência autorreferencial, a perspectiva de uma escrita/leitura dis simulada faz da ficção o objeto de uma crença que suspeita de si mesma.

O que disso nos interessa é a dis simulação enquąto noção chave em DFW. É como se, em sua obra, houvesse uma voz implícita nos in dagando o tempo inteiro: vocês re almente estão me levando a sério (uma vez que eu mesmo não sei se estou)? Quanto à eficácia retórica desse recurso, o que se ganha é proporcional ao que se perde: quanto mais o autor e o leitor expli citam se enquanto personagens im plicados, menos a ficção sustenta o seu caráter propriamente fictício, assumindo então um aspecto meta ficcional. Mas não seria esse aspec to o mais fictício de todos? É o que aparece com maior clareza no con to "Good Old Neon", parte da cole tânea Oblivion:

Tudo bem, não importa o que você pensa. Quero dizer, provavelmente isso importa para você, ou você acha que importa - não é isso o que eu quis dizer por "não importa". O que eu quero dizer é que não im porta o que você pensa sobre mim, porque, apesar das aparências, isso nem sequer é sobre mim (WALLA CE, 2004, p. 152).

O narrador é Neal, um jovem suicida que nos conta o que o levou a se matar. Mas a questão do "pa radoxo da fraude" como causa úni ca do suicídio é declarada logo no primeiro parágrafo, ao passo que no último, enquanto Neal está refle tindo sobre as contradições póstu mas de ele ainda estar ali conver sando conosco, a perspectiva pula e paira sobre DFW diante de um ál bum de fotos do ensino médio, olhando fixamente para a foto de Neal. O personagem que só aparece no final está em silêncio, tentando desviar se de sua própria consciên cia que lhe diz que querer imaginar com empatia o que se passa na mente de outra pessoa é não apenas 
impossível, mas também digno do mais cínico riso. $O$ conto se encerra com "a parte mais real, duradoura e sentimental dele [DFW] ordenando que a outra parte ficasse em silên cio, como se olhasse nos olhos e dis sesse, quase em voz alta, 'nem mais uma palavra"' (WALLACE, 2004, p. 181).

Ora, seria uma saída tipicamente metaficcional caso o narrador recu asse para a subjetividade do autor (como é frequente, por exemplo, em Paul Auster). Mas não é isso o que ocorre em Good Old Neon. Em bora saibamos que DFW é o autor da história, o narrador o descreve apenas como um personagem bem sucedido na vida, em contraste com a fraude de Neal. A princípio, por tanto, nada indica que a história que acabamos de ler foi "inspirada na vida" de Wallace. Mas, ao mes mo tempo, o "paradoxo da fraude" consiste justamente em simular uma personalidade confiante e au têntica, num esforço equivalente à fraude assim ocultada. Com efeito, entre o narrador que nos adverte que "isso nem sequer é sobre mim" e o personagem secundário que é meramente aludido ao final, o re curso da dissimulação ganha con tornos wallaceanos.

Por um lado, "Good Old Neon". ilustra o esforço constante de DFW em revelar as contradições e insufi ciências inerentes a noções como "autêntico", "fraude", "identidade" etc. Por outro, vemos ali uma luta entre Neal, o suposto narrador pós tumo e niilista, contra o humanista DFW (cujos textos de não ficção reivindicam por relações humanas mais sólidas, empáticas, não aliena das), um autor silenciosamente im plicado em sua própria ficção, sen tado em uma poltrona reclinável, observando a foto de um suposto colega do ensino médio. Eis a luta entre a função autorreferencial do texto ficcional e a dissimulação co implicada entre leitor e autor. DFW é simultaneamente o fantasma de um narrador suicida e o persona gem vivo de si mesmo.

\section{A reconstrução de DFW em O fim da turnê}

A literatura está polvilhada de des troços dos homens que se importa ram além do razoável com a opinião dos outros (WOOLF, 2014, p. 42).

Wallace tinha apenas 34 anos quando publicou o romance Graça Infinita (Infinite Jest), um sucesso inesperado que lhe rendeu o título de melhor escritor norte americano de sua geração. Tal ocasião é o pano de fundo de $O$ fim da turnê (James Ponsoldt, 2015), filme roteirizado por Donald Margulies, que se inspi rou no best -seller de David Lipsky (2010), Although of course you end up becoming yourself, cuja premis sa consiste no dilema entre como DFW era percebido e como ele dizia ser. Com efeito, o filme pro põe/resulta de uma sobreposição interpretativa: Ponsoldt interpre tando Margulies interpretando Lip sky interpretando DFW interpre tando o mundo e a si mesmo.

A cena inicial mostra Lipsky re cebendo a notícia do suicídio de 
DFW, o que o leva a recuperar, em suas fitas cassete, o registro em áu dio de uma entrevista fracassada que ele havia feito doze anos atrás para a revista Rolling Stone. Regre dimos então à época em que o jo vem jornalista solicitava a seu edi tor a tarefa de entrevistar DFW, $\mathrm{Cu}$ ja súbita fama era invejada por Lip sky (que acabara de publicar, na quele ano, o seu primeiro roman ce), embora reconhecesse em DFW o gênio que todos os críticos diziam que ele era. $O$ filme se atém, a par tir de então, ao conturbado diálogo entre Lipsky e DFW, ocorrido du rante os cinco dias da última via gem de lançamento de Graça Infini ta.

No primeiro dia, Lipsky evita a frieza de um inquérito jornalístico; em vez disso, mostra se interessado em algo como uma iluminação lite rária. Cauteloso, poucas vezes vai direto ao ponto, tentando antes de cifrar o entrevistado. Mas embora Lipsky imaginasse deparar $\sim$ se com um ser fora do comum, o indivíduo que ele conhece é apenas alguém que gosta de ir ao shopping, apai xonado por seus cachorros e com plexado com a fama recente. Ao ser questionado sobre drogas, DFW precisa reiterar que o'seu pior vício era o de assistir TV. Demonstrando desconforto, ele também tece pou cas palavras sobre sua batalha con tra a depressão. Não resta, enfim, nada de glamoroso ou excêntrico em sua vida. O recluso DFW só saía de casa para praticar dança numa igreja batista.

Só que o jornalista insiste em desconfiar de que a insegurança emocional de DFW, atrelada à sua bandana colorida, é um modo de despistar o gênio escondido. De um lado, o protagonista se recusa a dar respostas simples, preocupando se a todo momento em como suas pa lavras poderiam soar e, pior, em como a percepção de Lipsky sobre suas palavras poderia ser recebida pelo público. De outro, o jornalista acredita que DFW é arguto o sufici ente para manter sua genialidade velada. Assim, a desconfiança de Lipsky passa a competir com a de DFW em relação ao seu interroga dor. Eles chegam a brigar, o repór ter o acusa de mentiroso, e o escri tor veta o acesso aos pais e amigos para entrevistas complementares. No último dia, em ato de desespero, Lipsky aproveita a ausência do en trevistado e começa a vasculhar sua casa, registrado em seu gravador tudo o que vế, dos imãs da geladeira ao revestimento de pano do vaso sanitário.

$O$. filme se encerra frustrando qualquer expectativa, como a de Lipsky, por uma genialidade escon dida por trás da máscara DFW. Mas a discussão que fica em aberto não é tanto acerca do peso da fama ou "dos engodos de um mito literário, ' mas sobre o quão legítimo era o es forço de DFW em não querer pare cer o gênio que todos queriam ver nele. Porque embora seja nítida sua insatisfação para com essa imagem construída sobre ele (veiculada, no caso, por Lipsky), também é eviden te a pretensão intelectual de DFW em parecer ingênuo. Esta é, afinal, a questão que Lipsky levanta em seu livro: ele era um gênio que se dis 
farça de ingênuo ou um ingênuo tratado como gênio? E parece ter sido essa visada de Lipsky, privilegi ada no filme, que suscitou o aborre cimento de alguns dos guardiões da honra de "St. Dave" (apelido que muitos leitores de DFW ainda utili zam para expressar cérta deificação do autor). Os confidentes próxịmos a ele, como a viúva Karen Green, bem como a editora Little Brown, liderada pelo editor Michael Pi etsch, repudiaram o filme enquanto este ainda estava em fase de produ ção:

\begin{abstract}
David teria odiado a ideia se ele ti vesse sido consultado, e o fato de que a produção pôde ser levada adiante porque ele está morto me deixa muito, muito triste. Qualquer um que tenha lido a obra de David sabe o quão atormentado ele se sen tia em ser uma figura pública e sua avassaladora ansiedade de estar do lado errado da tela. A existência de uma mitificação dessa breve passa gem de sua vida me parece uma afronta a ele e às pessoas que amam a sua escrita (PIETSCH apud ZEIT CHIK, 2015, s. p.).
\end{abstract}

Em contrapartida, mencionando os muitos livros póstumos publica dos com a assinatura de DFW, a escritora Maria Bustillos (2014, s. p.) questiona: "Por que ainda se es pecula sobre 'a insondável questão do que Wallace teria ou não teria consentido se ainda estivesse vivo?". De fato, não parece ser exatamente o consentimento do autor o que está em jogo. Antes de o filme começar a ser filmado, segundo Zeitchik (2015), Karen Green chegou a ofe recer a James Ponsoldt os direitos de qualquer livro de DFW, na espe rança de que fosse a voz de Walla ce, e não a suspeita versão de Lip sky, a sér transposta à tela. $\mathrm{O}$ advo gado do Fundo Literário DFW, por sua vez, acusou os cineastas de esta rem desfrutando de uma reputação que não lhes pertence (ZEITCHIK, 2015). Ao mesmo tempo, em seu depoimento Why The End of the Tour isn't really about my friend $D F W$, o escritor Glenn Kenny (2015, s. p.) critica a caricatura de "um gênio que era simplesmente muito puro e sagrado para este mundo", argumentando que os ci neastas não conseguiram entender a sutil ambivalência de DFW em relação a tais questões.

O que está em disputa, portanto, é similar ao mote que sustenta o enredo do filme: as diferentes ver sões de um mesmo personagem com o acréscimo do suicídio anun ciado desde o início, um apelo sem o qual o filme soaria desproposita do, comó se não tivesse nada a di zer. A mensagem central, a princí pio, não deixa de ser esta: quanto à genialidade e ao suicídio, DFW não tinha nada a dizer. Mas tal versão não é de todo plausível, caso con trário ele não se preocuparia tanto com o que diz, e com o que ele não deveria ter dito, e sobre como ele poderá ser interpretado etc. Logo, mais do que não ter nada a dizer, DFW queria provar que tudo o que se diz sobre ele está errado - inclu indo talvez o próprio filme, alvo daqueles que se dizem' autorizados a falar em nome de. Wallace.

Entre versões e aversões, enfim, DFW mostra -se ora enigmático, ora 
dissimulado. Ele era um viciado em TV que criticava a corrosiva aliena ção televisiva. Graça Infinita fez dele um cânone literário e, ao mes mo tempo, um ícone pop. Além dis so, era um sujeito angustiado, como sublinha Galindo (20.14, s. p.): "Angustiado para se entender, para entender os outros, para entender como cada um de nós pode tentar entender os outros, como cada um pode entender como os outros ten tam entender os outros, e nós e (aaargh!) assim por diante". Mas, ao mesmo tempo, há algo de simu lado em suas obsessões meticulosa mente cultivadas, um mistério aná logo à "graça" de Joelle van Dyne, personagem de Graça Infinita, cujo rosto, escondido por um véu após um acidente de ácido, é descrito ora como horripilante, ora como insu portavelmente belo.

A graça não reside apenas no que possui graça, mas também parte de quem a glorifica, tanto quanto de quem a renega. No fundo, toda gra ça não passa de acidente, ainda que o aspecto acidental possa ser minu ciosamente simulado. É como DFW dissimula em $O$ fim da turnê: "Os escritores não são mais espertos do que as outras pessoas. Eles são apenas mais atraentes em' sua estupidez ou em sua confusão".

\section{Considerações (in)finitas: o suicídio de quem?}

Pensamos prolongar a vida de um romance com uma adaptação, e na verdade não fazemos outra coisa senão construir um mausoléu onde apenas uma pequena inscrição so bre o mármore lembra o nome de quem já não está mais ali (KUNDE RA, 2006, p. 144).

Mais do que gênio ou ingênuo, DFW queria parecer "engenhoso", noção oriundá do latim ingenium: disposição inata de engendrar, compor, forjar. Somente a perspec tiva romântica poderia cindir essa noção em duas: o gênio, de um la do, e a ingenuidade, de outro ${ }^{8}$. In versamente, DFW parece recompor um trocadilho mais antigo, algo próximo daquele que Homero esta belece na Odisseia entre a palavra outis (ninguém) e o termo mètis (astúcia) ${ }^{9}$. O célebre ardil de Ulisses em se denominar "ninguém" para enganar o Ciclope não se reduz a um mero disfarce (ele poderia ter adotado qualquer outro nome), mas se sobressai pela ambiguidade. DFW, por sua vez, embora não se faça de inexistente, procura des vencilhar se de tudo o que as pes soas atribuem ao seu nome. Mas, tal comó Ulisses retornando a Ítaca disfarçado de mendigo, DFW sabe que a dissimulação é também um modo de ser flagrado, reconhecido, identificado.

Noutros termos, compreender a dissimulação a partir daquilo que êla não é, ou seja, em oposição à identidade do autor que teria domí nio sobre tal procedimento, seria manter se no jogo identitário ao qual DFW se furta. A dissimulação não pretende anular a identidade, mas torná la clandestina, opaca, desconhecida. Tratá se de advogar pelo direito de ser outro, de renun ciar aos seus próprios termos, culti vando certa identidade antes como 
estratégia para torna la, ela pró pria, imperceptível. Não que a ma nobra seja necessariamente enga nadora, pois ela parte das condições paradoxais de uma identidade que só consegue insinuar se à medida que desconstrói a si mesmá. É uma questão de admitir o aspecto impes soal de dizer se "eu", reconhecen do o como um processo desde o' início ficcional, o mesmo presente na criação de mitos e personas.

Sob esse prisma, DFW talvez nunca tenha sido quem ele dizia ser. Mas quem ele dizia ser? Quem ele de fato era. Ora, seu esforço era o de evidenciar o disparate inevitá vel entre o que se diz e o que se é, revelando que aquilo que nos pare ce mais coeso ou coerente é exata mente o que pode haver de mais enganador. Eis a estranha sinceri dade de DWF: ele fingia ser um personagem de si mesmo, descolan do se das expectativas e retroce dendo a uma incoerência de fundo que lhe é constitutiva.

No entanto, não há personagem que não responda a um drama que o enreda: as narrativas construídas sobre o mito DFW são simultanea . mente a condição e o reflexo de uma retórica dissimulada. Tal retó rica, a princípio, parece operar de modo similar a uma anamorfose visual $^{10}$. A dissimulação wallacea na, nesse sentido, tende a despertar o interesse pela decodificação de uma mensagem oculta.

Mas, olhando com atenção, nunca houve nada a ser decifrado, ne nhuma imagem reconhecível. Em constante deslocamento, DFW está o tempo todo fingindo. Com efeito, posto que "ficção" partilha etimo logicamente do mesmo radical que "fingimento", é possível encarar a dissimulação wallaceana como uma potência fabuladora, um modo pe culiar de encenar, dramatizar e produzir a ambiguidade entre o in ventado e o verossímil, entre o aci dental e o intencional, entre a graça e o ardil.

No filme de Ponsoldt, DFW diz que não quer ser um desses caras em eventos literários dizendo "Sou escritor!'Sou escritor!". Então ele se questiona: "E se eu acabar me tor nando uma paródia disso mesmo?". Tarde demais: ao cometer suicídio, Wallace finalmente tornou se DFW.
8 Trata $\sim$ se de uma deformação óptica em que, "através do deslocamento do observador para um determi nado ângulo, a imagem se torna reconhecível" (FERREIRA, 2016 p. 154).

\section{Do you end up becoming yourself? The character David Foster Wallace}

Abstract: This article proposes a reflection on the literary myth tied to the name David Foster Wal lace after the suicide of the author. This reflection elects as a target the version portrayed in The End of the Tour (James Ponsoldt, 2015), a film repudiated by the family and close colleagues of Wallace. At first, I justify the choice of facing DFW as a character. Next, I discuss the key notion of dissimulation in DFW, which elucidates the dilemma between who he claimed to be and the possible character of himself. Finally, I return to the controversy surrounding the mentioned film and I propose the Wallacean dissimulation as a strategy for fiction that praises the ambiguity.

Keywords: David Foster Wallace; dissimulation; character of self. 


\section{Referências}

BOOTH, Wayne C. The Rhetoric of Fiction. Chicago: The University of Chicago Press, 1983.

BUSTILlos, Maria. The Dead Cannot Consent. In: The Awl, Apr. 24, 2014. Dispo nível em: $<$ https://www.theawl.com/2014/04/the dead cannot $\sim$ consent/ > . Aces so em: 04 set. 2018.

CARVALHO, Ana Cecília. A toxidez da escrita como um destino da sublimação em David Foster Wallace. In: Psicologia USP, jul./set. 2010, v. 21, n. 3, p. 513 530.

COHEN, Samuel; KONSTANTINOU, Lee (Eds.). The Legacy of David Foster Wallace. Iowa: University of Iowa Press, 2012.

DERRIDA, Jacques. A escritura e a diferença. São Paulo: Perspectiva,'1971.

DURAS, Marguerite. Escrever. Rio de Janeiro: Rocco, 1994.

FERREIRA, Helena. Entre a realidade e o engano: as anamorfoses na comunicação visual. In: Visualidades, v. 14, n. 1, p. 150 171, jan./jun. 2016.

GAGNEBIN, Jeanne Marie. Lembrar escrever esquecer. São Paulo: Ed. 34, 2006.

GALINDO, Caetano. Eu e você segundo David Foster Wallace. Revista Piauí, n. 98, nov. 2014. Disponível em: <http://piaui.folha.uol.com.br/materia/eu e -voce segundo david foster $\sim$ wallace/>. Acesso em: 04 set. 2018.

GILES, Paul. Sentimental Posthumanism: David Foster Wallace. In: Twentieth Centu ry Literature, v. 53, n. 3, p. 327 344, 2007.

HOLLAND, Mary K. Succeeding Postmodernism: Language and Humanism in Con temporary American Literature. New York: Bloomsbury, 2013.

KELLY, Adam. David Foster Wallace and the New Sincerity in American Fiction. In: HERING, David (Ed.). Consider David Foster Wallace: Critical Essays. Los Angeles, Austin: Sideshow Media Group Press, 2010, p. 131 146.

KENNY, Glenn. Why The End of the Tour isn't really about my friend David Foster Wallace. The Guardian, Jul. 29, 2015. Disponível em:

$<$ https://www.theguardian.com/books/2015/jul/29/why the - end of - the -tour isnt $\sim$ really $\sim$ about $\sim$ my $\sim$ friend david foster $\sim$ wallace> $>$. Acesso em: 04 set. 2018.

KONSTANTINOU, Lee. No Bull: David Foster Wallace/and Postironic Belief. In: CO HEN, Samuel; KONSTANTINOU, Lee (Eds.). The Legacy of David Foster Wallace. Iowa: University of Iowa Press, -2012, p. 83 112.

KUNDERA, Milan. A cortina: ensaio em sete partes, São Paulo: Cia. das Letras, 2006. LIPSKY, David. Although of course you end up becoming yourself. New York: Broadway Books, 2010. 
MAX, D. T. The unfinished: David Foster Wallace's struggle to surpass "Infinite Jest". In: The New Yorker, March 9, 2009. Disponível em:

$<$ https://www.newyorker.com/magazine/2009/03/09/the unfinished $>$. Acesso em: 04 set. 2018.

OLIVEIRA, Juliana Michelli S. A máquina extraviada: a fabricação de mitos no conto de José J. Veiga. In: ALMEIDA, Rogério de; BECCARI, Marcos. Fluxos Culturais. arte, educação, comunicação e mídias. São Paulo: Faculdade de Educação da Universida de de São Paulo, 2017, p. 216 230.

RICOEUR, Paul. Tempo e narrativa - Vol. III. o tempo narrado. São Paulo: WMF Martins Fontes, 2010.

Escritos e Conferências II: hermenêutica. São Paulo: Loyola, 2011.

ROACHE, John. Marginalia after Modernism: the case of David Foster Wallace. Tese de Doutorado (Filosofia). Manchester: School of Arts, Languages and Cultures of The University of Manchester, 2015.

WALLACE, David Foster. A supposedly fun thing I'll never do again: Essays and Ar guments. New York: Little, Brown and Company, 1997.

. Oblivion: Stories. New York: Little, Brown and Company, 2004.

2005 .

. Breves entrevistas com homens hediondos. São Paulo: Cia. das Letras,

WOOLF, Virginia. Um teto todo seu. São Paulo: Tordesilhas, 2014.

ZEITCHIK, Steven. How 'End of the Tour' became a very David Foster Wallace kind of film. Los Angeles Times, Jul. 22, 2015. Disponível em:

$<$ http://www.latimes.com/entertainment/movies/la $\sim \mathrm{ca} \sim \mathrm{mn} \sim$ tour $\sim$ david foster

wallace 20150726 story.html>. Acesso em: 04 set. 2018.

$\underline{\text { Referência fílmica }}$

O FIM DA TURNÊ (The End of the Tour). Direção: James Ponsoldt. Produção: Mod ern Man Films, Anonymous Content, Kilburn Media. Estados Unidos, 2015. 106 $\min$. 